\title{
Clínica: impasses e desconcertos ${ }^{1}$
}

\section{Julio Hirschhorn Gheller ${ }^{2}$}

Antes da formação psicanalítica trabalhei por vários anos como psiquiatra e psicoterapeuta. Falarei de experiências que abrangem todo este percurso. Vou me referir a situações que provocaram perturbações da minha função analítica, abordando aspectos da destrutividade humana.

\section{Situação 1}

Na residência de Psiquiatria comecei por um estágio em enfermaria feminina. O meu supervisor apresentou as pacientes que eu iria acompanhar. Ele se deteve na descrição de uma delas, a quem diagnosticava como portadora de depressão em nível psicótico. Tentei, algumas vezes, conversar com ela, mas sua atitude era negativista. Não fazia contato espontâneo e não respondia a nenhuma pergunta. Seu rosto expressava angústia, ainda que tomando altas doses de medicação antidepressiva. Eu me deparava com um impressionante retrato da dor mental. Passada uma semana, aconteceu o impacto desconcertante. Ela, que continuava apática e abúlica, não aceitando participar de nenhuma atividade terapêutica, surpreendeu a todos. Saiu do imobilismo para a ação, ateando fogo às próprias vestes. Mesmo em ambiente hospitalar, conseguiu atentar contra a própria vida, tendo que ser encaminhada para o setor de queimados, onde veio a falecer. Ludibriou a vigilância e atingiu o seu intento final, produzindo profundo sentimento de impotência e a aguda percepção de nossos limites.

\section{Situação 2}

Já no consultório, recebi um paciente depressivo. Retraído, falava pouco, sempre com semblante sisudo e triste. $\mathrm{O}$ tema era um só: não se conformava com a decisão de sua esposa, que havia saído de casa, disposta a se separar. Mal a psicoterapia começou, a

\footnotetext{
${ }^{1}$ Este trabalho foi apresentado na mesa "Clínica: impasses e desconcertos" com Roosevelt S. Cassorla no I Simpósio Bienal "O mesmo, o outro: Psicanálise em movimento" da Sociedade Brasileira de Psicanálise de São Paulo.

${ }^{2}$ Analista didata da Sociedade Brasileira de Psicanálise de São Paulo.
} 
frequência teve que ser reduzida para apenas uma vez por semana devido a alegadas limitações financeiras e de tempo.

Após dois meses, o mal-estar persistia e havia pouco progresso na elaboração de sua questão. Fui, então, atingido por um golpe terrível. Certa noite, o plantonista de um pronto-socorro me telefonou, pedindo urgente avaliação para o paciente, que lá chegara após violenta discussão com sua mulher. Revoltado com a intransigência dela, que não abria mão da separação, acabou por agredi-la brutalmente, causando-lhe ferimentos fatais.

Meio zonzo, como que nocauteado pela notícia, me dirigi ao hospital. Encontrei o paciente absolutamente tranquilo. A descarga de agressividade o havia apaziguado. Isto me deixou chocado. Era algo demasiado para a minha limitada capacidade de acolhimento e compreensão. Não poderia atendê-lo mais. A violência, seguida por inusitada calma - que cheguei a interpretar, erroneamente, como a frieza de um psicopata - me causou inapelável rejeição. Ideias persecutórias passavam pela minha cabeça, como o temor de que o episódio viesse a afetar minha reputação profissional. De todo modo, ele seria detido após a alta hospitalar. Três semanas depois, me avisou que se mudaria para sua cidade de origem. Tinha sido liberado e lá cuidaria da defesa para o processo que corria contra ele. Respirei aliviado ao ser dispensado de minha função terapêutica.

Penso, hoje em dia, que eu realmente não tinha condições emocionais para analisar alguém que cometera um homicídio. Não era capaz de sintonizar com o teor de sofrimento de um provável personagem interno: o menino desamparado, infeliz e cheio de ódio ao objeto que o abandonara. A decisão da esposa o levou ao desvario. Transtornado pelo ciúme, explodiu violentamente, matando a mulher, que se não fosse dele, não seria de mais ninguém. $\mathrm{O}$ entendimento mais claro de aspectos clivados da personalidade só me foi possível tempos depois. Naquela época eu não conseguia enxergar o menino desamparado. Só enxergava o assassino que tirou a vida de quem não o queria mais. Alguém que, simplesmente, escolhera seguir seu rumo sem ele.

\section{Situação 3}

Entrevistei uma paciente simpática e comunicativa. Parecia um atendimento promissor. Ledo engano; logo percebi quão equivocada fora a primeira impressão. Já na primeira 
sessão, ela afirmou estar apaixonada por mim e propôs um relacionamento amoroso. Fiquei perplexo diante da inesperada reação transferencial, tão intensa quanto prematura. Tomado de surpresa, balbuciei uma interpretação tosca, dizendo que ela, provavelmente, podia ter se sentido bem acolhida por mim e, portanto, estaria "misturando os canais", me confundindo com uma espécie de pai. Só consegui irritá-la com esta intervenção atabalhoada, a que ela reagiu prontamente, insistindo na argumentação de cunho sedutor. Notei que estava contaminado por um envaidecimento narcísico ao ser cortejado pela jovem mulher. Contudo, logo sobreveio uma perturbação crescente com o assédio que não cessava. Ela voltou à carga no horário seguinte. Atordoado, me senti em apuros para concatenar as ideias. Hesitante nas novas interpretações, me vi acuado como um pugilista no canto do ringue, quando ela - com a maior naturalidade - me ofereceu a indicação de um advogado para tratar de meu divórcio, pois soubera que eu era casado. Diante do absurdo da proposta, reafirmei o limite de minha disponibilidade, restrita à psicoterapia. Todavia, a colocação revelou-se infrutífera. Tanto que, não encontrando saída para prosseguir trabalhando a/na transferência, chegamos a um impasse. A análise foi abortada, sendo interrompida, praticamente sem começar. Outra vez experimentei o alívio de quem escapava de uma grande encrenca. Este desfecho implicou nova sensação de fracasso. O lado positivo, em termos de aprendizado, era me fazer sair - dolorosamente - de um estado de ilusão, próprio de um narcisismo grandioso, de quem se acha mais do que realmente é.

Reflexões posteriores abriram espaço para a ampliação da minha compreensão. Aquela paciente tão articulada, falante e segura de si atuava uma parte psicótica da personalidade, caracterizada por arrogância, onipotência e negação da realidade, acarretando em transferência narcísica de cunho erótico e total impermeabilidade para questionar os seus atos. Eu estava - com a passagem por hospitais - relativamente habituado a lidar com pacientes francamente psicóticos. Entretanto, me faltava uma apreensão mais sofisticada para discriminar traços psicóticos em alguém que não exibisse o quadro psiquiátrico de psicose, com sua sintomatologia mais exuberante. Ainda precisava desenvolver a função de continência para processar aspectos transferenciais maciços, que atacassem a minha capacidade de pensar. Atributos desejáveis para o analista, tais como flexibilidade mental, rapidez de elaboração, jogo de cintura, refinamento de observação e senso de humor tendem a se desenvolver com o tempo. Também vim a conhecer o poder de identificações projetivas exitosas no âmbito 
de uma transferência psicótica. Eu estava sendo induzido a complementar o roteiro delineado pelas projeções da paciente sedutora. Como o sujeito atrapalhado, que é tocado pelo desejo do outro, fui arrastado por emoções opostas à concomitante percepção realista do acontecimento.

\section{Situação 4}

Atendia uma analisanda em processo bastante morno. Ela reportava basicamente as frustrações de seu relacionamento com um homem casado. Tratava-se de pessoa sem atributos especiais que a distinguissem.

Um aspecto logo passou a me intrigar. Ela provinha de família humilde e trabalhava como funcionária de segundo escalão em uma empresa de porte médio. Não obstante, levava uma vida de pessoa abastada. Seus programas indicavam condição financeira privilegiada. Não fazia nenhuma ostentação. Pelo contrário, estes detalhes apareciam somente de passagem nos seus relatos. O mistério finalmente se esclareceu. Ela me contou que participava, em sua firma, de um esquema de cobranças superfaturadas, tendo enriquecido por meio do desvio de verbas. A falcatrua acontecia há anos e ela já pensara em deixar o esquema, mas não sabia como. Experimentei um abalo desagradável. Ela, de forma deliberada e reiterada, cometia delitos com o objetivo de auferir vantagens materiais indevidas, algo que se chocava com meus princípios. Eu me vi às voltas com a dificuldade de avaliar a analisabilidade de alguém que, propositalmente, desconsidera a lei. É assunto sempre difícil. Acredito que deva ser avaliado caso a caso.

Nesta ocasião consegui sustentar a posição analítica, apesar de minhas objeções éticas. Refleti a respeito, admitindo que todos nós, seres humanos, somos falhos. Mesmo que esta noção não apagasse a realidade do ilícito por ela praticado, permitiu-me continuar o trabalho, levando em conta - principalmente - o que se desencadeou logo em seguida. A revelação deu novo impulso às suas associações e a paciente começou a relembrar o passado. Debruçou-se sobre um assunto até então pouco explorado. Examinou a história de sua infância, em que seu pai abusava das filhas. A mãe não o enfrentava e não as defendia. Assim pudemos conversar sobre o sentido do comportamento presente, relacionando-o com as recordações daquele tempo. Se o tabu do incesto não era respeitado em sua família, todas as regras e normas de conduta poderiam vir a ser 
burladas no futuro e de forma abrangente. Como vítima de abuso, ela, inconscientemente, queria se vingar. Renegava a lei e se considerava com direito a uma compensação pelos sofrimentos do passado. A partir do conjunto de elaborações surgidas, foi esboçando um sentido de autocrítica mais aguçado. Com uma visão mais clara dessas configurações intrapsíquicas, parou a análise, fugindo do conflito de ambivalência e culpa que se instalava.

A transgressão do tabu do incesto, englobando a recusa da lei, a negação da castração e da diferença de gerações, me remete à questão da pulsão de morte, conceito controvertido, mas de inegável valor do ponto de vista metafórico. Aparecia no caso com o desprezo pela ética e o objetivo de levar vantagem a qualquer preço. Em "Malestar na cultura" Freud, argumentando sobre a inclinação humana para a agressão, nos lembra que "o homem é o lobo do próprio homem", podendo espoliar o outro de seus bens, aproveitar-se sexualmente dele sem consentimento e causar-lhe toda sorte de humilhações e sofrimentos. Hostilidade e destrutividade, não raro com requintes de sadismo e crueldade, fazem parte da natureza humana.

\section{Situação 5}

E por falar em pulsão de morte, penso em outra variedade de sua manifestação, exemplificando com material clínico.

Um executivo me procurou, mobilizado pelo término de um namoro. Um elemento que acabou sobressaindo nos nossos encontros foi sua forma de me tratar como mero prestador de serviços. A um olhar microscópico eu era alguém contratado apenas para lhe entregar bons resultados. Do contrário, não lhe seria útil. Ele podia faltar, atrasar, não acertar os honorários na data combinada e eu deveria me contentar em saber que “isto não tinha nada de pessoal”. Deixar de pagar acontecia - por mero esquecimento posto que ele era um indivíduo ocupado, com diversos assuntos importantes para resolver. A interpretação do componente depreciativo que eu captava na relação, quando mencionada, era rechaçada como se eu estivesse "vendo coisas", dando importância exagerada a fatos corriqueiros. Por fim, interrompeu a análise, com uma breve mensagem de whatsApp. Convidado a conversar pessoalmente para elaborar ao vivo o encerramento do processo, de imediato recusou o encontro. 
Vislumbro aí um exemplo de desligamento e desinvestimento relacional, através da operação da função desobjetalizante, postulada por Green como agente da pulsão de morte. Como resultado, vínculos são atacados, predominando uma configuração de indiferença afetiva, de nítido traço utilitário. Assim, pessoas são facilmente descartáveis. Os objetos são descatexizados por efeito de ação que os destitui de investimento significativo. Simultaneamente à desobjetalização, a análise era sabotada por sentimentos invejosos - evidentemente negados - do paciente. Isto implicava - em outra vertente do traço mortífero - desvalorizar o meu empenho com ele para concluir que não necessitava mais de mim.

\section{Palavras finais}

Em suma, expus vestígios da destrutividade em algumas de suas modalidades de expressão:

1. Auto e hetero-agressividade;

2. Onipotência, arrogância, negação da realidade;

3. Identificações projetivas exitosas;

4. Negação da castração, recusa e transgressão da lei;

5. Desinvestimento e desobjetalização;

6. Inveja.

Estes aspectos convergem para a repetição de vivências frequentemente provenientes do inconsciente não recalcado. Precisam ser assinalados e interpretados, em busca de seu significado intrapsíquico e intersubjetivo. Pulsões conectadas a situações traumáticas precoces permanecem em estado bruto e - quando não ligadas - podem ser atualizadas, inclusive na transferência, conforme exposto nos exemplos descritos. Diante delas, nós analistas, imperfeitos e relativos que somos, estamos sujeitos a fracassos. Nessas ocasiões, o melhor que podemos fazer é admitir a precariedade inerente à nossa condição humana e procurar aprender com os erros.

\section{Referências}

Green, A. (1988). Pulsão de morte, narcisismo negativo, função desobjetalizante. In $A$ Pulsão de Morte. São Paulo, Editora Escuta. (trabalho original publicado em 1986). 